\title{
气孔运动中 $\mathrm{pH}$ 对保卫细胞壁弹性模量的影响
}

\author{
杨敦 (12)，赵杨 ${ }^{2} ，$ 朱果利 ${ }^{(2 *}$ \\ (1) 中国热带农业科学院环境与植物保护研究所, 农业部热带农林有害生物人侵监测与控制重点开放实验室, 海南省热带农业有害生物监 \\ 测与控制重点实验室, 儋州 571737 ; \\ (2) 中国农业大学生物学院植物生理学与生物化学国家重点实验室, 北京 100193 \\ * 联系人, E-mail: glzhu2009@gmail.com
}

2011-06-15 收稿, 2011-08-05 接受

国家自然科学基金资助项目(39870075 和 39600090)

\begin{abstract}
摘要 保卫细胞壁的特性对气孔运动有重要的影响. 以前的研究多集中于保卫细胞壁的解剖 结构, 对气孔运动中保卫细胞壁物理性质的改变了解很少. 本研究以蚕豆叶片表皮条为材料, 运用细胞压力探针技术, 对气孔运动中不同 $\mathrm{pH}$ 下的保卫细胞壁弹性模量 $(\varepsilon)$ 进行了测量. 研究 发现, 当 $\mathrm{pH}$ 从 8.60 降至 6.50 时, 保卫细胞壁的弹性模量从 $7.098 \mathrm{~Pa}$ 降至 $5.690 \mathrm{~Pa}$. 气孔运动 中, 较低的保卫细胞壁弹性模量有利于保卫细胞改变体积, 进而有助于气孔运动的完成. 从保 卫细胞通过调控细胞壁 $\mathrm{pH}$ 改变细胞壁弹性模量的角度来分析气孔运动机理, 对于完善气孔运 动机理假说, 进而深刻理解气孔运动, 具有重要的意义.
\end{abstract}

\section{关键词}

弹性模量

保卫细胞壁

细胞压力探针

$\mathrm{pH}$

气孔运动
气孔运动对陆生植物有重要的作用. 通过气孔 的开合, 植物可完成光合作用、呼吸作用和蒸腾作用 等重要的生理功能. 大多数陆生植物的气孔是由 一对肾形的保卫细胞组成, 通过保卫细胞膨压的改 变, 气孔张开或关闭 ${ }^{[1,2]}$. 当保卫细胞膨压增加时, 保卫细胞壁外侧的拉伸大于内侧的拉伸 ${ }^{[3 \sim 6]}$. 这种不 均匀的拉伸使得保卫细胞向外侧弯曲, 从而在 2 个保 卫细胞之间产生气孔孔径. 保卫细胞壁必须具有较 高的强度来承受气孔张开时膨压的增加，同时也要 具有较强的韧性以便于气孔关闭膨压减少时恢复形 变. 以前的研究多集中于保卫细胞壁的解剖结构和 分子基础 ${ }^{[3 \sim 9]}$, 对气孔运动中保卫细胞壁物理性质的 改变了解较少. 保卫细胞壁的物理性质可通过细胞 壁的弹性模量 $(\varepsilon)$ 来衡量, $\varepsilon$ 反映了细胞壁的弹性 ${ }^{[10]}$. 较低的 $\varepsilon$ 值表示细胞壁具有较大的弹性. 在一定的 膨压作用下, 具有较低 $\varepsilon$ 值的细胞壁比具有较高 $\varepsilon$ 值的 细胞壁有更大的形变. 通过调节保卫细胞壁的弹性模 量来影响气孔运动, 可能是一种重要的气孔运动调节 方式.
曾被用来研究植物水分生理的细胞压力探针是 研究气孔运动的重要工具 ${ }^{[1144]}$. 细胞压力探针不仅 能够直接测量高等植物细胞的细胞膨压 $(P)$ 、弹性模 量和水导率 (Lp), 还可以测量气孔运动过程中保卫细 胞壁弹性模量的改变.

$\mathrm{pH}$ 是气孔运动中重要的调节因子. 以前的研究 发现, 升高 $\mathrm{pH}$ 能促使气孔关闭, 并且 $\mathrm{ABA}$ 处理可使 细胞质的 $\mathrm{pH}$ 升高 ${ }^{[15 ~ 17]}$. 但是, 气孔运动中 $\mathrm{pH}$ 对保 卫细胞壁物理性质的影响目前尚无相关报道.

本研究以蟇豆为材料, 运用细胞压力探针技术 测量不同 $\mathrm{pH}$ 下气孔保卫细胞壁弹性模量的变化. 结果显示, 降低 $\mathrm{pH}$ 可明显降低保卫细胞壁的弹性 模量. 通过调节 $\mathrm{pH}$ 来降低保卫细胞壁的弹性模量进 而促进气孔运动, 可能是气孔运动中一种重要的调 节方式.

\section{1 材料与方法}

(i ) 实验材料. 寔豆 (Vicia faba L.) 种子浸种 12 $\mathrm{h}$ 后催芽 2 3 d, 播种于人造土壤(草碳土与蛭石体积

英文版见: Yang Y, Zhao Y, Zhu G L. pH induced elastic modulus of guard cell wall in stomatal movement. Chinese Sci Bull, 2011, 56, doi: 10.1007/s11434011-4798-Z 
比为 $3: 1$ )中, 生长室温度为 $23^{\circ} \mathrm{C}$ (光照) $/ 16^{\circ} \mathrm{C}$ (黑暗), 相对湿度为 40\% 60\%, 每天光照 $14 \mathrm{~h} \mathrm{(6:00} \mathrm{20:00),}$ 光源为金属卤化物灯, 光强为 $80 \sim 100 \mu \mathrm{mol} \mathrm{m} \mathrm{m}^{-2} \mathrm{~s}^{-1}$. 3 4 周龄的龺豆苗供实验用.

（ii）虫豆叶片表皮条的孵育和气孔开度测量. 3 4 周龄的虫豆苗, 从上往下取最上面第 1 片完全展 开叶, 撕取叶片的下表皮. 在有光照的条件下, 表皮 条分别孵育在 $\mathrm{pH} 6.50$ 和 8.60 的缓冲液 $(\mathrm{pH} 6.50,10$ mmol, Mes/Tris; pH 8.60, 10 mmol, Hepes/Tris)中 30 min, 期间轻轻摇动表皮条去除气泡. 孵育后的表皮 条四周用胶带固定在充满相应缓冲液的培养血里. 把培养血放在带标尺的显微镜下测量表皮条上的气 孔开度.

(iii) 保卫细胞膨压 $P$ 和弹性模量 $\varepsilon$ 的测量及计 算. 细胞压力探针的使用及保卫细胞膨压 $P$ 和弹性 模量 $\varepsilon$ 的测量参考 Franks ${ }^{[11]}$ 和 Steudle ${ }^{[12]}$ 的方法, 略 有改动. 弹性模量 $\varepsilon$ 的测量依照公式 $\varepsilon=V \cdot \Delta P / \Delta V^{[18]}$, 保卫细胞的体积 $V$ 通过在显微镜下测量保卫细胞后 计算获得. 压力冲动 $\Delta P(0.03 \sim 0.05 \mathrm{MPa})$ 通过压力探
针获得. 每一个压力冲动 $\Delta P$ 相应的细胞体积变化 $\Delta V$, 通过测量压力探针针尖的油水界面移动距离, 然后计算获得.

\section{2 结果与分析}

\section{$2.1 \mathrm{pH} 8.60$ 时气孔孔径、保卫细胞膨压 $P$ 和弹性 模量 $\varepsilon$ 的测量}

虫豆表皮条在 $\mathrm{pH} 8.60$ 的缓冲液中孵育 $30 \mathrm{~min}$ 后固定在培养血里, 用带标尺的显微镜测量气孔的 开度为 $8.34 \mu \mathrm{m}$, 同时测量并计算细胞体积 $V$ (图 1(a), 表 1). 然后用细胞压力探针的毛细管尖端扎入保卫 细胞, 此时保卫细胞的细胞液会进入探针的毛细管 内, 与探针毛细管内的硅油接触产生油水界面 (图 1(b)). 用压力探针把油水界面推回到细胞壁附近, 记 录油水界面的位置(图 1, 位置 1), 测得此时细胞膨压 $P$ 为 $0.228 \mathrm{MPa}$ (图 1(c)). 再用压力探针迅速地做一 个负压力冲动 $\Delta P$, 同时记录此时油水界面的位置(图 1(d), 位置 2). 根据位置 1 和位置 2 的距离计算得细 胞体积变化 $\Delta V$. 根据以上数据, 利用公式计算获得
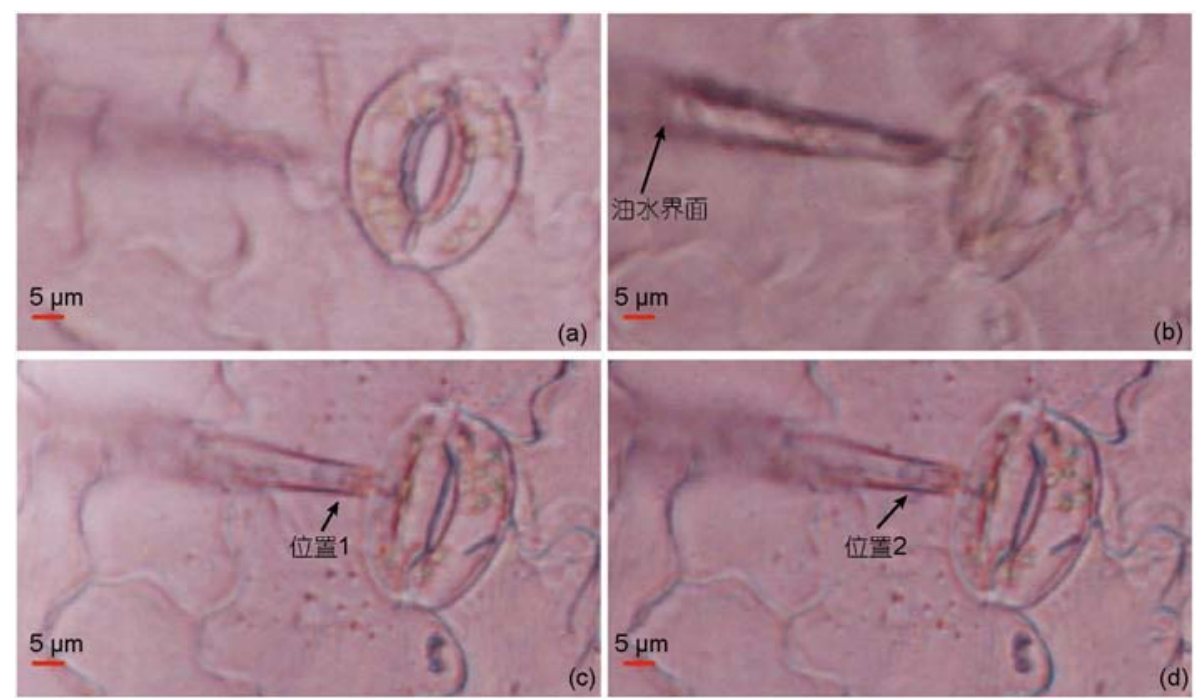

图 $1 \mathrm{pH} 8.60$ 时保卫细胞壁弹性模量 $\varepsilon$ 的测量

(a) 气孔开度和保卫细胞体积 $V$ 的测量; (b) 压力探针刚扎入保卫细胞时的油水界面; (c) 测量细胞膨压和油水界面的位置 1 ;

(d) 负压力冲动 $\Delta P$ 后油水界面的位置 2

表 $1 \mathrm{pH}$ 分别为 8.60 和 6.50 时保卫细胞的膨压及弹性模量 $\varepsilon$

\begin{tabular}{cccc}
\hline $\mathrm{pH}$ & 气孔孔径 $(\mu \mathrm{m})$ & 细胞膨压 $P(\mathrm{MPa})$ & 弹性模量 $\varepsilon(\mathrm{MPa})$ \\
\hline 8.60 & 8.34 & 0.228 & 7.098 \\
6.50 & 9.76 & 0.244 & 5.690 \\
\hline
\end{tabular}



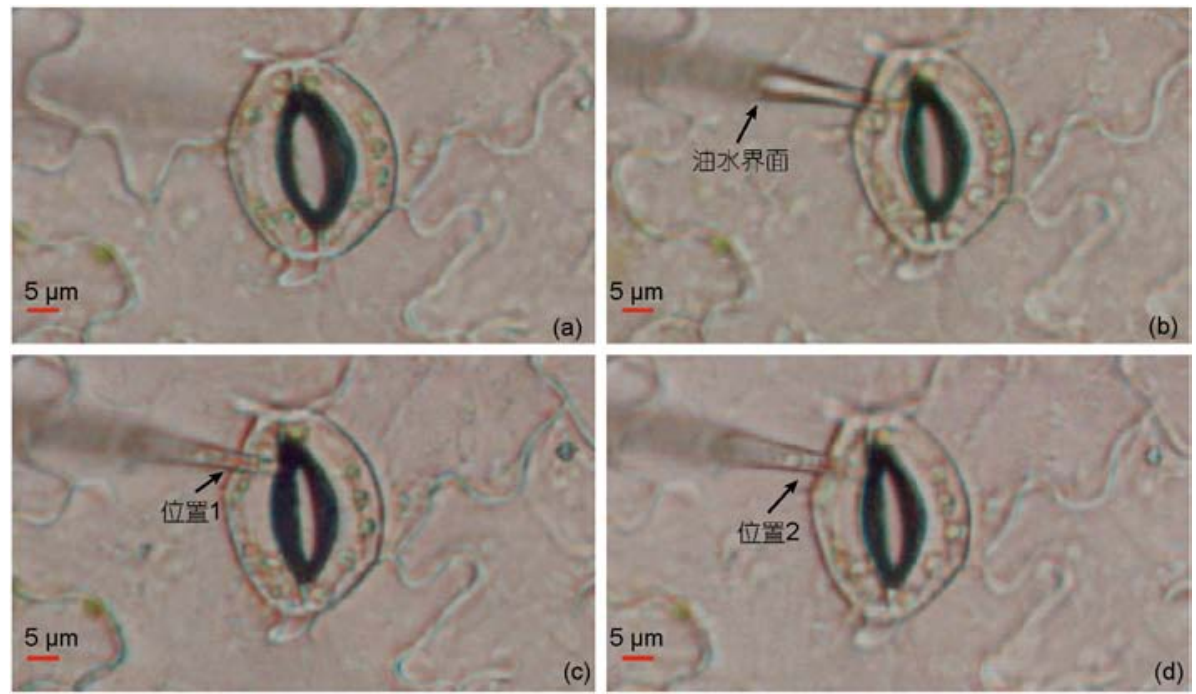

图 $2 \mathrm{pH} 6.50$ 时保卫细胞壁弹性模量 $\varepsilon$ 的测量

(a) 气孔开度和保卫细胞体积 $V$ 的测量; (b) 压力探针刚扎人保卫细胞时的油水界面; (c) 测量细胞膨压和油水界面的位置 1 ;

(d) 负压力冲动 $\Delta P$ 后的油水界面的位置 2

保卫细胞壁的弹性模量 $\varepsilon$ 为 7.098 .

\section{2 pH 6.50 时气孔孔径、保卫细胞膨压 $P$ 和弹性 模量 $\varepsilon$ 的测量}

虫豆表皮条在 $\mathrm{pH} 6.50$ 的缓冲液中孵育 $30 \mathrm{~min}$ 后固定在培养血里, 用带标尺的显微镜测量气孔的 开度为 $9.76 \mu \mathrm{m}$, 同时测量并计算细胞体积 $V$ (图 2(a), 表 1). 然后用细胞压力探针的毛细管尖端扎入保卫 细胞, 此时保卫细胞的细胞液会进入探针的毛细管 内, 与探针毛细管内的硅油接触产生油水界面 (图 2(b)). 用压力探针把油水界面推回到细胞壁附近, 记 录油水界面的位置(图 2, 位置 1), 测得此时细胞膨压 $P$ 为 $0.244 \mathrm{MPa}$ (图 2(c)). 再用压力探针迅速地做一 个负压力冲动 $\Delta P$, 同时记录此时油水界面的位置(图 2(d), 位置 2). 根据位置 1 和位置 2 的距离计算得细 胞体积变化 $\Delta V$. 根据以上数据, 利用公式计算获得 保卫细胞壁的弹性模量 $\varepsilon$ 为 5.690 .

\section{3 讨论}

细胞压力探针被广泛用来研究高等植物细胞水 平上的水分生理和保卫细胞的功能. 以前的研究发 现, 当细胞膨压增大时, 细胞的弹性模量可从 $2 \mathrm{MPa}$ 增大至 $40 \mathrm{MPa}^{[19]}$. 本研究发现, 在气孔开度和保卫 细胞的膨压相似的条件下, 当 $\mathrm{pH}$ 从 8.60 降到 6.50 时, 保卫细胞的弹性模量有明显的降低(7.098 5.690 $\mathrm{MPa})$. 较低的弹性模量有利于保卫细胞产生形变, 从而更有利于气孔运动. 保卫细胞可能通过调节 $\mathrm{pH}$ 来降低弹性模量, 从而有利于气孔运动. 本研究对于 深人了解气孔运动机理具有重要的意义.

$\mathrm{pH}$ 是一种重要的细胞信号因子, 能促进气孔开 放 ${ }^{[1,20]}$, 且 $\mathrm{pH}$ 可以激活膨胀素(expansin)的活性 ${ }^{[21]}$. 膨 胀素能重排细胞壁的动态结构, 调节细胞壁的弹性. 本研究发现的 $\mathrm{pH}$ 对保卫细胞壁弹性模量的影响是否 是通过膨胀素起作用, 还有待于进一步的实验证实.

\section{参考文献}

1 Hetherington A M, Woodward F I. The role of stomata in sensing and driving environmental change. Nature, 2003, 424: 901-908

2 Fischer R A. The relationship of stomatal aperture and guard-cell turgor pressure in Vicia faba. J Exp Bot, 1973, 24: 387-399

3 Aylor D E, Parlange J Y, Krikorian A D. Stomatal mechanics. Am J Bot, 1973, 60: 163-171

4 Wu H I, Sharpe P J H. Stomatal mechanics II: Material properties of guard cell walls. Plant Cell Environ, 1979, 2: 235-244

5 Sharpe P J H, Wu H I. Stomatal mechanics: Volume changes during opening. Plant Cell Environ, 1978, 1: 259-268 
6 Wu H, Sharpe P J H, Spence R D. Stomatal mechanics. III. Geometric interpretation of the mechanical advantage. Plant Cell Environ, 1985, 8: 269-274

7 Jones L, Milne J L, Ashford D, et al. Cell wall arabinan is essential for guard cell function. Proc Natl Acad Sci USA, 2003, 100: 11783-11788

8 Majewska-Sawka A, Munster A, Rodriguez-Garcia M I. Guard cell wall: Immunocytochemical detection of polysaccharide components. J Exp Bot, 2002, 53: 1067-1079

9 Zhang X Q, Wei P C, Xiong Y M, et al. Overexpression of the Arabidopsis $\alpha$-expansin gene AtEXPA1 accelerates stomatal opening by decreasing the volumetric elastic modulus. Plant Cell Rep, 2010, 30: 27-36

10 Zimmermann U, Husken D. Theoretical and experimental exclusion of errors in the determination of the elasticity and water transport parameters of plant cells by the pressure probe technique. Plant Physiol, 1979, 64: 18-24

11 Franks P J. Use of the pressure probe in studies of stomatal function. J Exp Bot, 2003, 54: 1495-1504

12 Steudle E. Pressure probe techniques: Basic principles and application to studies of water and solute relations at the cell, tissue, and organ level. In: Smith J A C, Griffiths H, eds. Water Deficits: Plant Responses from Cell to Community. Oxford: Bios Scientific Publishers, 1993. $5-36$

13 Tomos A D, Leigh R A. The pressure probe: A versatile tool in plant cell physiology. Annu Rev Plant Physiol Plant Mol Biol, 1999, 50: $447-472$

14 Tomos D. The plant cell pressure probe. Biotechnol Lett, 2000, 22: 437-442

15 Wilkinson S, Davies W J. Xylem sap pH increase: A drought signal received at the apoplastic face of the guard cell that involves the suppression of saturable abscisic acid uptake by the epidermal symplast. Plant Physiol, 1997, 113: 559-573

16 Bacon M A, Wilkinson S, Davies W J. pH-regulated leaf cell expansion in droughted plants is abscisic acid dependent. Plant Physiol, 1998, 118: $1507-1515$

17 MacRobbie E A C. Signal transduction and ion channels in guard cells. Philos Trans R Soc Lond B Biol Sci, 1998, 353: 1475-1488

18 Philip J. The osmotic cell, solute diffusibility, and the plant water economy. Plant Physiol, 1958, $33: 264$

19 Franks P J, Buckley T N, Shope J C, et al. Guard cell volume and pressure measured concurrently by confocal microscopy and the cell pressure probe. Plant Physiol, 2001, 125: 1577-1584

20 Bittisnich D J, Entwisle L, ONeales T F. Acid-induced stomatal opening in Vicia faba L. and the role of guard cell wall elasticity. Plant Physiol, 1987, 85: 554-557

21 Cosgrove D J. Loosening of plant cell walls by expansins. Nature, 2000, 407: 321-326 